\title{
The Role and Mechanism of Exercise for Prevention of Myocardial Fibrosis in Diabetes
}

\author{
Qi-e Zhu \\ Hubei Province Key Laboratory on Cardiovascular, Cerebrovascular, and Metabolic Disorders, \\ Hubei Institute of Science and Technology, Xianning 437100, China
}

412165585@qq.com

Keywords: Exercise, Diabetes, myocardial fibrosis, TGF- $\beta 1$, Smad4.

\begin{abstract}
Aims. TGF- $\beta 1$ plays a role in promoting the transformation of myocardial fibrosis. Smad4 has important functions in maintaining tissue stability and inhibiting cardiac hypertrophy. In this study, we investigated the effect of exercise on TGF- $\beta 1 / \mathrm{Smad} 4$ and myocardial fibrosis in diabetes. Methods. Male C57BL/6 and db/db mice in exercise group were conducted swimming training for 10 weeks. Mice in control group were sedentary. After exercise intervention, heart weight, body weight and blood glucose were observed. TGF- $\beta 1$, Smad4 and MMP9 in Cardiac tissues were tested through Western blot. The mRNA lever of TGF- $\beta 1$ and Smad4 were tested through qRT-PCR. Results. Compared to $\mathrm{db} / \mathrm{db}$ sedentary group, blood glucose in $\mathrm{db} / \mathrm{db}$ exercise group reduced significantly ( $\mathrm{P}$ $<0.05)$, Heart Index was higher in $\mathrm{db} / \mathrm{db}$ exercise group than that of $\mathrm{db} / \mathrm{db}$ sedentary group $(\mathrm{P}<0.05)$. 10 weeks' swimming training reduced the level of TGF- $\beta 1$ mRNA, protein and Smad4, MMP9 protein in $\mathrm{db} / \mathrm{db}$ mice significantly $(\mathrm{P}<0.05)$. Conclusion. Aerobic exercise can improve myocardial fibrosis in diabetes through TGF- $\beta 1 / \mathrm{Smad} 4$ pathway.
\end{abstract}

\section{Introduction}

Diabetic cardiomyopathy(DCM) is a common and greatly harmful complication of diabetes, characterized by structure abnormality and functional decline, myocardial ischemia, fibrosis, heart failure. By report, DCM is the dominate factor leading to mortality of diabetes[1]. Myocardial fibrosis is one of the important representation of organ damage, aerobic exercise can ameliorate myocardial fibrosis in diabetes[2], while the mechanism is not very clear, and the exact signal pathway is uncertain. Transferred Growth Factor $\beta 1$ (TGF- $\beta 1$ ) can promote myocardial fibroblast transformation and formation of myocardial collagen protein. The signal of TGF- $\beta 1$ transferred by Smads, among Smads families, Smad4 is the central molecule in TGF- $\beta 1$ signal transferring, moreover, Smad4 has very important physiological function in maintaining tissue stability and restraining myocardial hypertrophy. So, it is likely that the function state of TGF- $\beta 1 / \mathrm{Smad} 4$ is related with prevention and treatment of diabetes closely. This research aims to discuss the control effect of aerobic exercise to TGF- $\beta 1 / \mathrm{Smad} 4$ and impact on diabetic myocardial fibrosis, here we show that aerobic exercise down-regulates TGF- $\beta 1$ and Smad4, prevents myocardial fibrosis.

\section{Materials and Methods}

\subsection{Animals and Experimental Groups}

Male C57BL/6 wild-type mice and $\mathrm{db} / \mathrm{db}$ mice weighting $22.05 \pm 1.6 \mathrm{~g}$, 4-6weeks old, were obtained from the Center of Disease Control and Prevention of HuBei province, China, and were divided into four groups randomly( $\mathrm{n}=6$ per group): sedentary wild-type mice(control sedentary); exercised wild-type mice(control exercise); sedentary $\mathrm{db} / \mathrm{db}$ mice( $\mathrm{db} / \mathrm{db}$ sedentary); exercised $\mathrm{db} / \mathrm{db}$ mice $(\mathrm{db} / \mathrm{db}$ exercise $)$. Mice were maintained under a $12 \mathrm{~h}$ light $/ 12 \mathrm{~h}$ dark cycle at $22^{\circ} \mathrm{C}$, humidity at $60 \%-70 \%$, fed on standard rodent diet and water ad libitum, animal experiments were conducted under the guidelines of laboratory animals use and care for biomedical research issued by National Institutes of Health(No. 85-23, revised 1996). 


\subsection{Exercise Protocol}

Animals of two exercise groups(control exercise and $\mathrm{db} / \mathrm{db}$ exercise) engaged in a swimming program for 10 weeks. For water tank, the height is $40 \mathrm{~cm}$, the diameter is $50 \mathrm{~cm}$, water depth is $30 \mathrm{~cm}$, water temperature is $25^{\circ} \mathrm{C}$ to $28^{\circ} \mathrm{C}$. On the first day, mice swam 10 minutes, then duration was increased by 10 minutes/day, until a maximum of 40 minutes of swimming duration. From the fifth day, mice began the formal swimming training, 5 days per week and for 10 weeks.

\subsection{Determination of Heart Weight Index}

Mice heart was removed and washed at $4{ }^{\circ} \mathrm{C}$, then weighed after being dried, after body weight measurement, mice heart weight index(whole heart weight/body weight)were calculated. Next, the heart specimen was stored at $-80^{\circ} \mathrm{C}$ for western blot assay and polymerase chain reaction assay.

\subsection{Western Blot Analysis}

Cardiac tissues were collected and lysed in buffer laemmli(Bio-Rad), then the isolated protein were loaded in SDS-PAGE gel and separated via electrophoresis, next, the protein was transferred onto a polyvinyli-dene fluoride(PVDF) membrane(Millipore, Billerica, MA). After blocking with $5 \%$ skimmed milk, the membrane was incubated with primary anti bodies overnight at $4{ }^{\circ} \mathrm{C}$, followed by incubation with horseradish peroxidash (HRP) conjugated secondary antibody(Beyotime Biotech, Haimen, China) under room temperature for 2 hours. The protein bands were visualized by enhanced chemiluminescence(Applygen), band intensity was analyzed with ImageJ software and the bands were normalized to the internal standard.

\subsection{Quantitative Real Time PCR(Qrt-PCR) Refrigerator}

Heart issue was taken from $-80^{\circ} \mathrm{C}$ refrigerator and isolated using Trizol solution, qRT-PCR assay was performed according to the kit instructions. Primers were as follows: TGF- $\beta 1$ upstream primer, 5'-ATTCCTGGCGTTACCTTGG-3', downstream primer, 5'-AGCCCTGTATTCCGTCTCCT-3', Smad4 upstream primer, 5'-CAACATTCCTGTGGCTTCC-3', downstream primer, 5'-ATCCATTCTGCTGCTGTCCT-3'. The transcripts were checked with $2 \%$ agarose gel electrophoresis, all reactions were repeated three times, GAPDH was used to normalize targetgenes.

\section{Results}

\subsection{Swimming Training Prevented Cardiac Dysfunction of Diabetes}

We measured body weight and heart weight to get heart index to understand the influence of swimming training, we also measured blood glucose(table 1). We found that there were significant differences in blood glucose between $\mathrm{db} / \mathrm{db}$ exercise group and $\mathrm{db} / \mathrm{db}$ sedentary group $(\mathrm{P}<0.05)$, moreover, there were significant changes in Heart Index before and after swimming training in $\mathrm{db} / \mathrm{db}$ mice $(\mathrm{P}<0.05)$. The results above suggested that 10 weeks' swimming can improve blood glucose, reduce heart stress, even the overall body condition.

Table 1.Effect of exercise on heart function and blood glucose

\begin{tabular}{|c|c|c|c|c|}
\hline & $\begin{array}{c}\mathrm{n}=6 \\
\text { control sedentary }\end{array}$ & $\begin{array}{c}\mathrm{n}=6 \\
\text { control exercise }\end{array}$ & $\begin{array}{c}\mathrm{n}=6 \\
\mathrm{db} / \mathrm{db} \text { sedentary }\end{array}$ & $\begin{array}{c}\mathrm{n}=6 \\
\mathrm{db} / \mathrm{db} \text { exercise }\end{array}$ \\
\hline Body weight $(\mathrm{g})$ & $33.2 \pm 1.5$ & $28 \pm 2.2^{*}$ & $58.8 \pm 1.4^{*}$ & $45.64 \pm 1.2^{\#}$ \\
\hline Heart weight $(\mathrm{g})$ & $0.15 \pm 0.01$ & $0.15 \pm 0.02$ & $0.12 \pm 0.01^{*}$ & $0.15 \pm 0.02^{\#}$ \\
\hline Heart index & $0.45 \pm 0.01$ & $0.52 \pm 0.05$ & $0.20 \pm 0.11^{*}$ & $0.33 \pm 0.12^{\#}$ \\
\hline Blood glucose (mmol/L) & $5.78 \pm 0.6$ & $5.66 \pm 0.9$ & $13.4 \pm 1.02^{*}$ & $9.8 \pm 1.2^{\#}$ \\
\hline
\end{tabular}

Mean blood glucose, body weight and heart weight following 10 weeks of swimming training protocol. Animal numbers $(\mathrm{n}=6)$ in each group are presented. $※ \mathrm{P}<0.05$ vs control sedentary, \# $\mathrm{P}<$ $0.05 \mathrm{vs} \mathrm{db} / \mathrm{db}$ sedentary.

\subsection{Swimming Training Reduced TGF-B1in the Diabetic Myocardium}

Since cardiac dysfunction could be attributed to myocardiac fibrosis, we investigated the key cytokine which plays important role in occurrence and development of myocardiac fibrosis in mice hearts. Both TGF- $\beta 1 \mathrm{mRNA}$ and the level of TGF- $\beta 1$ protein increased significantly in $\mathrm{db} / \mathrm{db}$ 
sedentary group $(\mathrm{P}<0.05)$. Though 10 weeks' swimming training reduced them significantly $(\mathrm{P}<$ $0.05)$, it can not normalized TGF- $\beta 1 \mathrm{mRNA}$ and the protein level(Fig 1).
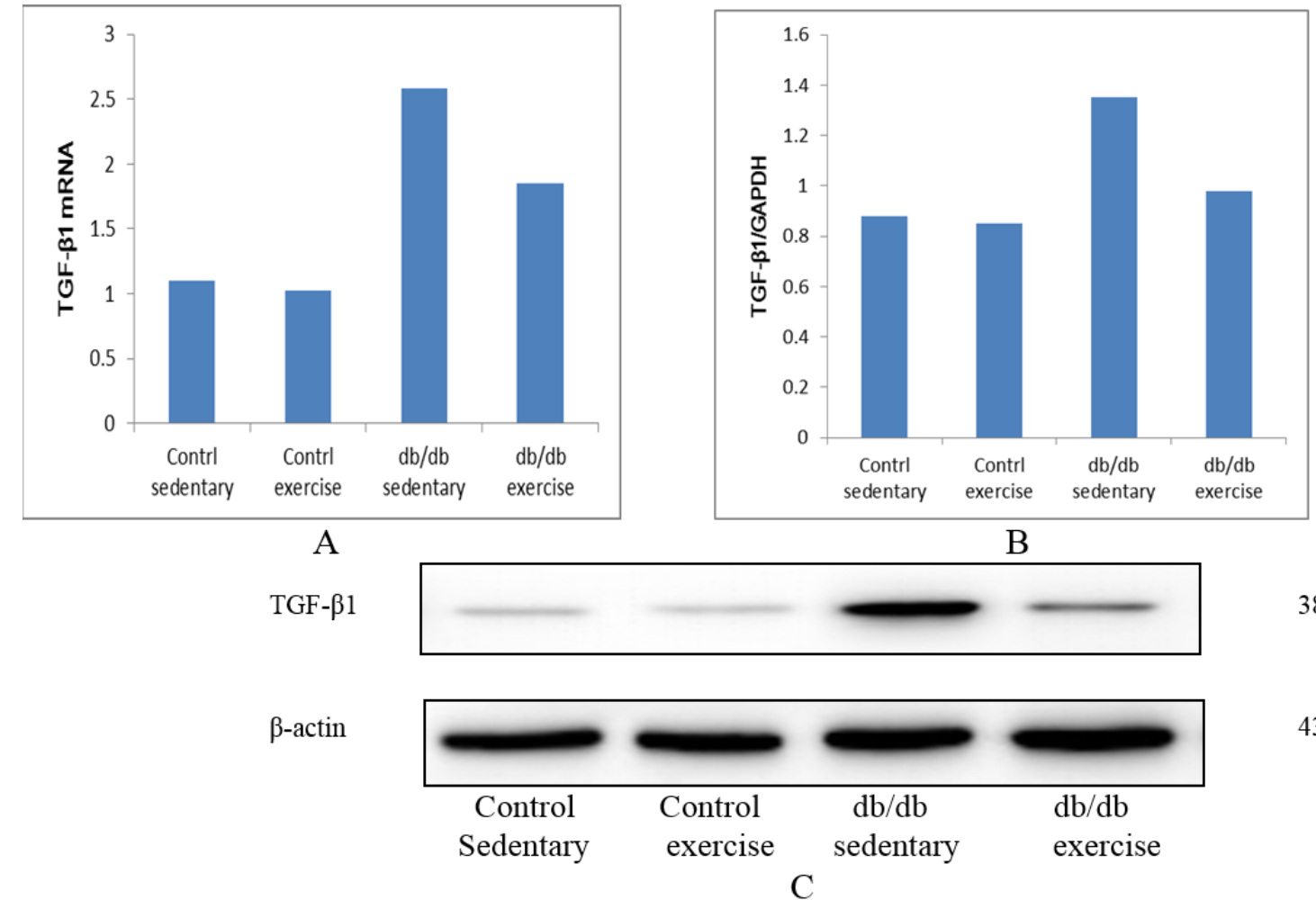

$38 \mathrm{KD}$

$43 \mathrm{KD}$

Fig.1 Effect of exercise on TGF- $\beta 1$, the TGF- $\beta 1$ was evaluated by qRT-PCR (A) and western blot (B and $\mathrm{C}$ ), $\mathrm{P}<0.05$ vs control sedentary, \# $\mathrm{P}<0.05 \mathrm{vs} \mathrm{db} / \mathrm{db}$ sedentary.

\subsection{Swimming Training Attenuated Smad4 in Diabetic Myocardium}

Smad4 is a key molecule in TGF- $\beta 1 /$ Smad signaling pathway, while there is not extensive research into it, we assayed both Smad4 mRNA and Smad4 protein, our research found that Smad4 mRNA in $\mathrm{db} / \mathrm{db}$ sedentary group is higher than that of in control sedentary $(\mathrm{P}<0.05)$, Smad4 protein in $\mathrm{db} / \mathrm{db}$ sedentary group is higher than that of in control sedentary, also, but 10 weeks' swi mming training reduces Smad4 protein significantly of $\mathrm{db} / \mathrm{db}$ mice $(\mathrm{P}<0.05)$, Smad4 mRNA does not changed by swimming significantly, these results indicated that mechanism of exercise controlling Smad4 is complicated(Fig 2). 


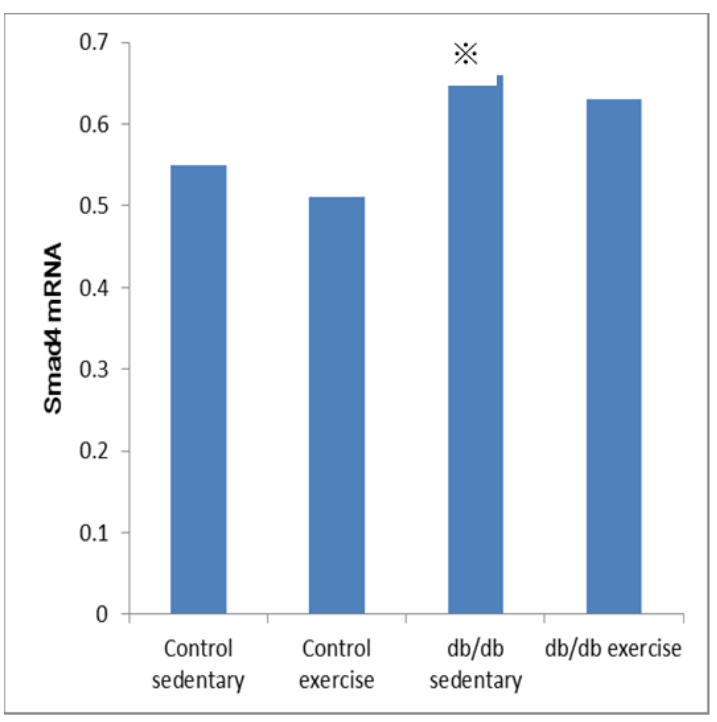

A

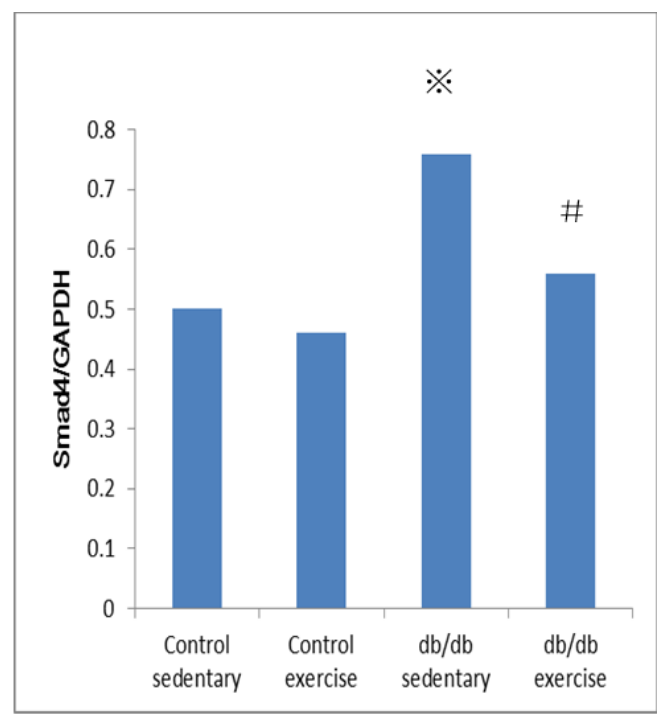

B

TGF- $\beta 1$

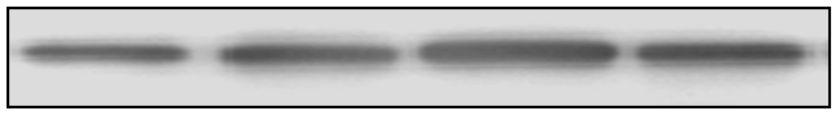

$38 \mathrm{KD}$

$\beta$-actin

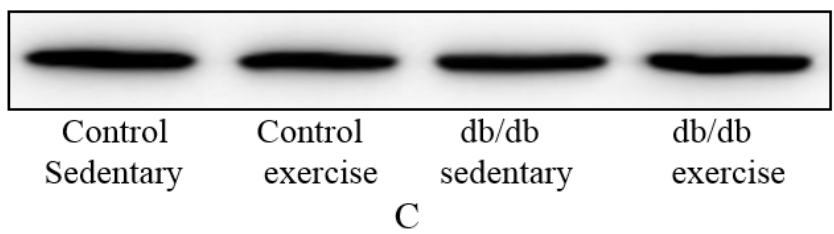

$43 \mathrm{KD}$

Fig.2 Effect of exercise on Smad4, the Smad4 was evaluated by Qrt-PCR (A) and western blot (B and C), $※ \mathrm{P}<0.05$ vs control sedentary, \# $\mathrm{P}<0.05 \mathrm{vs} \mathrm{db} / \mathrm{db}$ sedentary.

\subsection{Swimming Training Ameliorated MMP9 in Diabetic Myocardium}

MMP9(matrix metalloproteinase 9, MMP9) is positively related to the degree of myocardial fibrosis, we found that MMP9 is higher in diabetic myocardium significantly, while 10 weeks' swimming training can reduce it obviously $(\mathrm{P}<0.05)($ Fig3 $)$ 


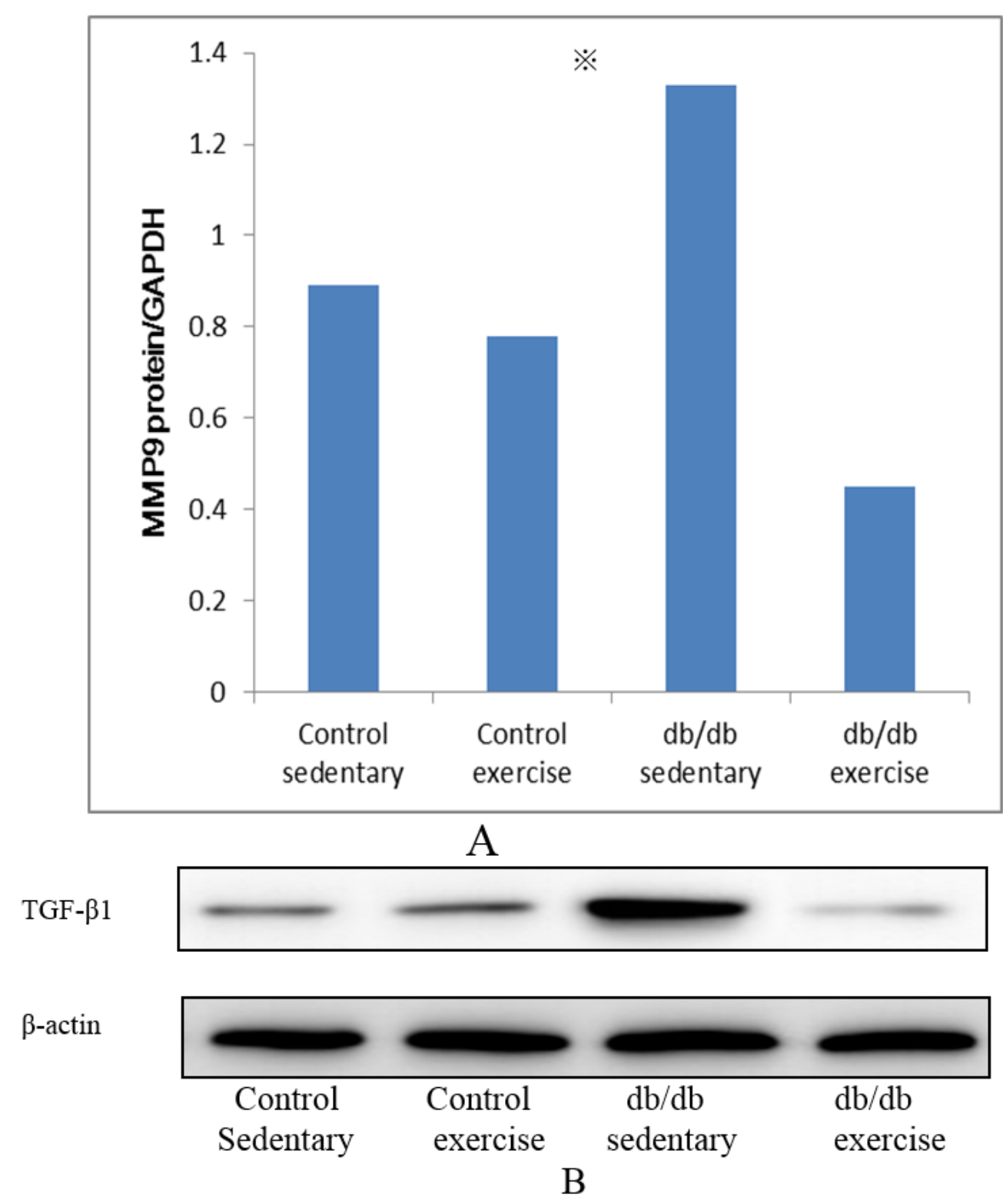

$38 \mathrm{KD}$

Fig.3 Effect of exercise on MMP9, the MMP9 was evaluated by western blot (A and $\mathrm{B}$ ), $※ \mathrm{P}<0.05$ vs control sedentary, \# $\mathrm{P}<0.05 \mathrm{vs} \mathrm{db} / \mathrm{db}$ sedentary.

\section{Discussion}

In this study, we investigated the effects of long-term swimming train on heart function and myocardial fibrosis in wild-type and $\mathrm{db} / \mathrm{db}$ mice, the results showed that $\mathrm{db} / \mathrm{db}$ mice got marked cardiac function impairment, further investigation showed that myocardial fibrosis appeared in $\mathrm{db} / \mathrm{db}$ mice. Total TGF- $\beta 1$ mRNA, TGF- $\beta 1$ protein, MMP9 protein levels were significantly higher in diabetes, however, 10 weeks' swimming training reduced them, moreover, exercise can control Smad4 on protein level but not on mRNA level in diabetes.

TGF- $\beta$ is a series of protein which is relative on structure, and plays a key role in remodeling and growth of extracellular matrix, growth and apoptosis of cell, maintenance of intracellular homeostasis etc $[3,4]$. TGF- $\beta 1$ is a member of TGF- $\beta$ families, some research demonstrated that varied or abnormal expression of TGF- $\beta 1$ would induce diabetic cardiomyopathy[5,6], TGF- $\beta 1$ can not only decreases degradation of extracellular matrix, but also increase synthesis and secretion, therefore, overexpression of TGF- $\beta 1$ can promote myocardial fibrosis development. In the present study, we observed that diabetes led to increased TGF- $\beta 1$ mRNA and protein, while the exercise protocol changed the tendency and male reduction of TGF- $\beta 1$ mRNA and protein. Consistent with previous 
finding on diabetic rats, 8 weeks' swimming training ameliorated the quantity of collagen in the left ventricle[7]. suggesting that exercise was able to reverse the adverse effect of TGF- $\beta 1$ on myocardium of diabetic mice, it is probably the mechanism that exercise ameliorates myocardial fibrosis in diabetes.

Smad4 is located in cytoplasm, and downstream of TGF- $\beta$, it is related to varieties of heart disease including myocardial fibrosis. The role signal transferring of Smads in TGF- $\beta$ pathway has crucial impact on myocardial fibrosis[8,9]. Among Smads, Smad4 is the center molecule in TGF- $\beta 1$ signal pathway. In the current study, diabetes influenced both Smad4 mRNA and protein, exercise training can enhance Smad4 protein in diabetic mice, but not Smad4 mRNA, suggesting that exercise training control Smad4 on protein level, not mRNA, the specific mechanism is awaiting further research. In addition, we observed MMP9 levels in healthy and diabetic mice, also the influence of exercise training, we found that diabetes caused MMP9 overexpression, but exercise training reversed this change.

\section{Acknowledgements}

This work was supported by the grant from Diabetes Special Fund of Hubei University of Science and Technology(2016-18XZ05).

\section{References}

[1]. Chavali V, Tyagi SC, Mishra PK: Predictors and prevention of diabetic cardiomyopathy. Diabetes Metab Syndr Obes Targets Ther 2013; 6:151-160.

[2]. Wang H, Bei Y, Lu Y, et al. Exercise Prevents Cardiac Injury and Improves Mitochondrial Biogenesis in Advanced Diabetic Cardiomyopathy with PGC-1 $\alpha$ and Akt Activation. Cell Physiol Biochem., 2015, 35(6):2159-2168.

[3]. Chen YG, Meng AM. Negative regulation of TGF-beta signaling in development. Cell Res, 2004, 14: 441-449.

[4]. Ouchi N, Ohishi M, Kihara S, et al. Association of hypoadiponectinemia with impaired vasoreactivity. Hypertension, 2003, 42(3):231-234.

[5]. Jiang C, Huang H, Liu J, et al. Fasudil, a rho-kinase inhibitor, attenuates bleomycin-induced pulmonary fibrosis in mice. Int J Mol Sci, 2012, 13(7):8293-8307.

[6]. Harmancey R, Taegtmeyer H. The complexities of diabetic cardiomyopathy: lessons from patients and animal models. Curr Diab Rep 2008; 8:243-248.

[7]. Da Silva E, Natali AJ, Silva MF, et al. Ventricular remodeling in growing rats with experimental diabetes: The impact of swimming training. Pathol Res Pract, 2013, 209(10):618-626.

[8]. Zhu XY, Daghini E, Rodriguez-Porcel M, et al. Redox-sensitive myocardial remodeling and dysfunction in swine diet-induced experimental hypercholesterolemia. Atherosclerosis, 2007, 193(1):62-69.

[9]. Xia Y, Lee K, Li N, et al. Characterization of the inflammatory and fibrotic response in a mouse model of cardiac pressure overload. Histochem Cell Biol, 2009, 131(4):471-481. 